\title{
PENENTUAN DIMENSI SUDU TURBIN DAN SUDUT KEMIRINGAN POROS TURBIN PADA TURBIN ULIR ARCHIMEDES
}

\author{
Herman Budi Harja ${ }^{1}$, Halim Abdurrahim ${ }^{2}$, Sigit Yoewono ${ }^{3}$, Hendi Riyanto ${ }^{4}$ \\ ${ }^{1}$ Politeknik Manufaktur Negeri Bandung, ${ }^{2}$ FTMD Institut Teknologi Bandung \\ Jalan Kanayakan No.21 Dago Bandung \\ E-mail : h_b_harja@yahoo.com
}

\begin{abstract}
Abstrak
Telah dilakukan penelitian penentuan dimensi sudu turbin dan sudut kemiringan poros turbin pada turbin ulir Archimedes. Penelitian ini melakukan kajian pada beberapa parameter turbin ulir yaitu penentuan dimensi sudu turbin dan sudut kemiringan poros turbin agar dihasilkan kinerja turbin optimum. Penentuan dimensi sudu turbin ulir mengikuti formulasi C.Rorres yang memaksimumkan volume air di antara kisar sudu turbin ulir. Dimensi sudu turbin ulir untuk potensi daya fluida head 2 meter dan debit 20 hingga 40 liter/detik yang dihasilkan memiliki spesifikasi: konstruksi rotor memiliki 2 buah sudu ulir, kisar ulir $413 \mathrm{~mm}$, radius sudu luar $\left(R_{o}\right) 408 \mathrm{~mm}$ dan radius sudu dalam $\left(R_{i}\right) 109 \mathrm{~mm}$. Kemudian dilakukan perhitungan panjang lintasan bentangan ulir agar menghasilkan kisar ulir sebesar $413 \mathrm{~mm}$. Panjang lintasan bentangan ulir dapat diperoleh dengan menggunakan dua cara yaitu perhitungan persamaan helix atau simulasi software gambar, kedua cara ini menghasilkan panjang lintasan ulir sebesar $802 \mathrm{~mm}$. Penentuan sudut optimum kemiringan poros turbin dihitung berdasarkan gaya berat dan gaya hidrostatis yang dihasilkan volume air di antara 2 sudu ulir, perhitungan ini mendapatkan sudut optimum kemiringan poros adalah $32^{\circ}$.
\end{abstract}

Kata kunci : head rendah, turbin ulir, kinerja , sudu turbin dan sudut kemiringan

\begin{abstract}
Research has been conducted and the determination of the dimensions of turbine blades on the turbine shaft tilt angle Archimedes screw turbine. This research coducted a study on several parameters to define optimum performance of screw turbine. it are the determination of the dimesions screw blade and the optimum angle of shaft slope.

Determination of dimensions screw blade was designed using Chriss Rorres formulation which maximizes the volume of water in screw turbin blade and made base from potential energy of water with 2 metres head and 20 to 40 litres/second of rate flow. It consists of 2 blades having $413 \mathrm{~mm}$ pitch, $408 \mathrm{~mm}$ radius of external blade $\left(R_{o}\right), 109 \mathrm{~mm}$ radius of internal blade $\left(R_{i}\right)$ and $346 \mathrm{~cm}$ long of turbine shaft. The length of screw trajectory can be obtained by using two methods, equation helix calculation and software simulation. Those methode produce the same result of $802 \mathrm{~mm}$.

Determination of the optimum angle of shaft slofe is defined by the water weight and hydrostatis force analysis. It is found out at $32^{\circ}$.
\end{abstract}

Key Word: low head, screw turbine, performance, screw blade and slope shaft. 


\section{PENDAHULUAN}

Potensi sumber energi air pada head sangat rendah $(<3$ meter $)$ yang banyak terdapat di wilayah Indonesia saat ini belum banyak dimanfaatkan karena terkendala oleh ketersediaan teknologi yang mampu memanfaatkannya. Oleh karena itu diperlukan pengembangan teknologi yang dapat memanfaatkan potensi sumber energi tersebut. Turbin ulir merupakan jenis turbin yang mampu bekerja pada head sangat rendah.

Dengan semakin berkurangnya sumber energi fosil, maka salah satu alternatif sumber energi yang bisa menggantikannya adalah sumber energi terbarukan, khususnya sumber energi terbarukan yang teknologi pemanfaatannya memerlukan investasi kecil. Pembangkit listrik tenaga mikro hidro (PLTMH), sistem konversi energi angin (SKEA) dan pembangkit listrik tenaga panas bumi (PLTP) adalah beberapa contoh sistem konversi energi yang memanfaatkan sumber energi terbarukan, namun tidak semuanya memerlukan investasi kecil.

PLTMH memanfaatkan potensi energi aliran air yang memiliki head dan debit tertentu menjadi energi listrik. Sampai saat ini banyak pemanfaatan air sebagai sumber energi listrik hanya pada potensi energi air dengan head tinggi dan/atau debit besar, padahal banyak daerah di Indonesia memiliki potensi energi aliran air sungai dengan head sangat rendah ( $<3$ meter). Oleh karena itu, diperlukan pengembangan jenis turbin yang dapat memanfaatkan potensi energi air dengan head sangat rendah. Beberapa jenis turbin air yang dapat bekerja pada head rendah adalah kincir air, turbin kaplan dan turbin ulir.

Penelitian ini mengkhususkan pada penentuan dimensi sudu turbin. Penentuan dimensi dan bentuk sudu turbin ulir akan mengacu pada formulasi Rorres. Pada dasarnya, formulasi pengoptimuman dimensi ulir Archimedes yang dilakukan oleh Chris Rorres adalah untuk penggunaannya sebagai pompa. Sedangkan perancangan pembuatan sudu ulir akan mengikuti persamaan helix dan simulasi perangkat lunak gambar teknik.

\section{TINJAUAN PUSTAKA}

Turbin Ulir Archimedes merupakan teknologi yang sejak zaman kuno telah ditemukan dan diterapkan sebagai pompa, dimana pada konstuksinya terdiri dari satu atau beberapa sudu berbentuk heliks yang terpasang pada poros dan berfungsi sebagai bucket bergerak untuk membawa air ke atas. Kemudian seiring dengan kebutuhan pemanfaatan sumber potensi energi air dengan head rendah, penggunaan ulir Archimedes diterapkan sebagai turbin air ${ }^{(1 ; 2)}$.

Prinsip kerja turbin ulir Achimedes ialah (lihat Gambar 1) :

- air dari ujung atas mengalir masuk ke ruang di antara kisar sudu ulir (bucket) dan keluar dari ujung bawah;

- gaya berat air dan beda tekanan hidrostatik dalam bucket di sepanjang rotor mendorong sudu ulir dan memutar rotor pada sumbunya dan

- rotor turbin memutar generator listrik yang disambungkan dengan ujung atas poros turbin ulir.

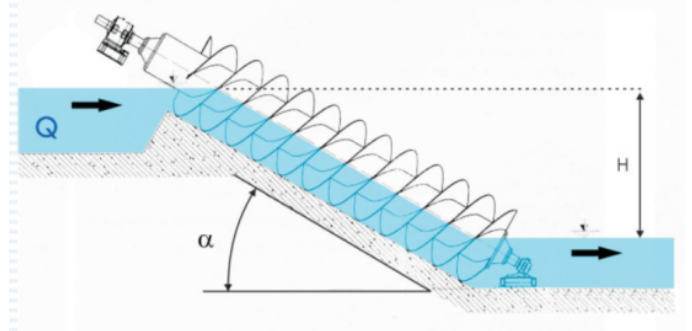

Gambar 1. Skematik turbin ulir ${ }^{(3)}$.

Oleh karena itu volume air dalam bucket harus dimaksimumkan agar menghasilkan efisiensi pembangkitan daya tertinggi. Adapun keuntungan turbin ulir dibandingkan dengan jenis turbin lain adalah sebagai berikut:

- Dapat dioperasikan pada head sangat rendah, hingga 1 meter;

- Dapat dioperasikan tanpa saringan dan tidak menganggu ekosistem sungai;

- Umur turbin lebih tahan lama terutama jika dioperasikan pada putaran rendah;

- Mudah dalam pengoperasian dan murah dalam perawatan;

- Memiliki efisiensi dan kehandalan yang tinggi (lihat Tabel 1);

- Mampu bekerja pada rentang variasi debit yang lebar (lihat Tabel 1 ). 
Pada Tabel 1 ditunjukkan perbandingan efisiensi turbin air jenis ulir Archimedes, turbin Kaplan (aksial), turbin Francis (sentrifugal) dan turbin Banki (cross flow) terhadap tingkat rendaman sudu dalam air. Tabel tersebut menunjukkan bahwa turbin ulir Archimedes mengungguli jenis turbin lain untuk seluruh kondisi rendaman. Efisiensi $25 \%$ dicapai pada tingkat rendaman $10 \%$ dan $87 \%$ pada tingkat rendaman $100 \%$.

Tabel 1. Perbandingan efisiensi berbagai jenis turbin air terhadap tingkat rendaman ${ }^{(3)}$.

\begin{tabular}{|l|c|c|c|c|c|c|c|c|c|c|}
\hline & \multicolumn{10}{|c|}{ Water engine filling } \\
\hline Water engine type & $10 \%$ & $20 \%$ & $30 \%$ & $40 \%$ & $50 \%$ & $60 \%$ & $70 \%$ & $80 \%$ & $90 \%$ & $100 \%$ \\
\hline Archimedean screw & 25 & $\mathbf{7 4}$ & 77 & $\mathbf{7 9}$ & $\mathbf{8 2}$ & $\mathbf{8 3}$ & $\mathbf{8 4}$ & $\mathbf{8 5}$ & $\mathbf{8 6}$ & $\mathbf{8 7}$ \\
Kaplan turbine & 15 & 70 & 85 & 88 & 90 & 90 & 90 & 90 & 88 & 85 \\
\hline Francis turbine & - & - & 15 & 58 & 72 & 78 & 82 & 82 & 82 & 80 \\
Banki turbine & - & 40 & 60 & 68 & 72 & 74 & 75 & 74 & 72 & 70 \\
\hline & \multicolumn{10}{c|}{ Water engine efficiency [\%] } \\
\hline
\end{tabular}

Daya Bangkitan Sumber Energi Air

Daya yang bisa dibangkitkan dari sumber energi air dapat dihitung dengan menggunakan persamaan (1) berikut ${ }^{(4)}$ :

$$
P=\eta \rho g H Q
$$

Lambang huruf $P$ mewakili potensi daya dalam satuan Watt $(W), \quad \eta$ menunjukkan efisiensi konversi energi ditentukan oleh jenis turbin yang digunakan untuk memanfaatkan sumber energi air $(0<\eta<1), \rho$ melambangkan massa jenis air $\left(1000 \mathrm{~kg} / \mathrm{m}^{3}\right), g$ adalah percepatan gravitasi $\left(9,81 \mathrm{~m} / \mathrm{s}^{2}\right)$ dan $Q$ adalah debit air $\left(\mathrm{m}^{3} / \mathrm{s}\right)$ serta $H$ adalah head air (m).

\section{Dimensi Turbin Ulir}

Geometri sebuah turbin maupun pompa ulir Archimedes ditentukan oleh dimensi luar dan dimensi dalam turbin (lihat Gambar 2).

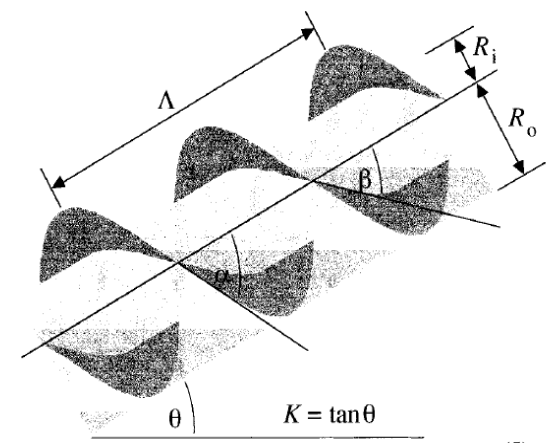

Gambar 2. Profil turbin ulir 2 sudu ${ }^{(5)}$.
Keterangan :

- $R_{i}$ : jari-jari dalam sudu ulir $\left(0<R_{i}<R_{o}\right)$

- $R_{o}$ : jari-jari luar sudu turbin

- $\Lambda$ : kisar ulir sudu turbin $\left(0 \leq \Lambda \leq 2 \pi R_{o} / K\right)$

- $K: \tan \theta$

- $\theta$ : sudut kemiringan poros turbin

- 6 : sudut ulir (pada posisi $\mathrm{R}_{\mathrm{i}}$ )

- $\alpha$ : Sudut ulir (pada posisi $\mathrm{R}_{\mathrm{o}}$ )

- $\quad N$ : Jumlah sudu $(1,2, \ldots)$

Dimensi luar turbin terdiri jari-jari terluar sudu ulir $R_{o}$, kisar ulir $A$, dan sudut kemiringan poros $\theta$. Dimensi luar ditentukan oleh lokasi penempatan ulir, material ulir yang akan digunakan dan debit air. Sudut kemiringan poros $\theta$ turbin umumnya antara $30^{\circ}$ sampai $60^{\circ}$

Sedangkan dimensi bagian dalam turbin meliputi jari-jari dalam $R_{i}$, jumlah sudu $N$, dan jarak antar sudu bila $N>1$. Dimensi dalam turbin bebas dipilih, sehingga pengoptimuman turbin ulir dapat dilakukan dengan mengubah dan memvariasikannya.

Panjang poros ulir $L$ dapat dihitung mengingat hubungan berikut :

$$
L=\frac{H}{R}
$$

Rorres menawarkan formulasi untuk menentukan dimensi-dimensi ulir Archimedes berdasarkan perhitungan pemaksimuman volume air di antara kisar sudu, volume maksimum tersebut dinyatakan dalam persamaan (3).

Pada volume maksimum tersebut, diameter dalam $R_{i}^{*}$ dapat diperoleh dari persamaan (4).

$$
R_{i}^{*}=\rho^{*} R_{0}
$$

Kisar ulir pada volume maksimum dinyatakan oleh persamaan (5)

$$
A^{*}=\frac{\pi R_{0} A^{*}}{R}
$$

Nisbah volume optimum $\boldsymbol{v}^{*}$, jari-jari optimum dan nisbah kisar optimum $N$ ditampilkan pada Tabel 2. Nisbah volume, nisbah jari-jari dan nisbah kisar didefinisikan pada persamaan (6), (7), (8) berikut ini : 


$$
\begin{aligned}
& v^{*}=\frac{V_{T}}{\pi R_{Q}^{2} A} \\
& \rho^{*}=\frac{R_{i}}{R_{Q}} \\
& \lambda^{*}=\frac{A K}{2 \pi R_{a}}
\end{aligned}
$$

Jumlah kisar $m$ yang diperlukan pada panjang poros turbin ulir $L$ untuk panjang kisar optimum $\AA^{*}$ dapat dihitung dengan persamaan (9).

$$
m=\frac{L}{\Lambda^{4}}
$$

Persamaan (2) s.d (9) bersama Tabel 2 digunakan untuk menentukan dimensi rancangan turbin ulir Archimedes dalam kegiatan penelitian ini.

Putaran turbin ulir maksimum $n_{\text {maks }}(\mathrm{rpm})$ dan hubungan antara dimensi kisar $\Lambda$ dan jarijari luar sudu $R_{o}$ untuk berbagai sudut kemiringan turbin dapat dinyatakan dalam persamaan (10) dan $(11)^{(6)}$.

$$
n_{\text {maks }}=\frac{50}{2 R_{0}^{2 / z}}
$$

\begin{tabular}{|c|c|c|c|c|}
\hline $\begin{array}{c}\text { Number of } \\
\text { blade } \\
\text { N } \\
\text { (1) }\end{array}$ & $\begin{array}{c}\text { Optimal } \\
\text { radius ratio } \\
\rho^{\times} \\
\text {(2) }\end{array}$ & $\begin{array}{c}\text { Optimal } \\
\text { pitch ratio } \\
\lambda^{\times} \\
\text {(3) }\end{array}$ & $\begin{array}{c}\text { Optimal } \\
\text { volume-per- } \\
\text { tum ratio } \\
\lambda^{*},\left(\mathrm{~N}, \mathrm{\rho}^{*}, \lambda^{*}\right) \\
\text { (4) }\end{array}$ & $\begin{array}{c}\text { Optimal } \\
\text { volume ratio } \\
v\left(\mathrm{~N}, \rho^{*}, \lambda^{*}\right) \\
(5)\end{array}$ \\
\hline 1 & 0,5358 & 0,1285 & 0,0361 & 0,2811 \\
\hline 2 & 0,5369 & 0,1863 & 0,0512 & 0,2747 \\
\hline 3 & 0,5357 & 0,2217 & 0,0598 & 0,2697 \\
\hline 4 & 0,5353 & 0,2456 & 0,0655 & 0,2667 \\
\hline 5 & 0,5352 & 0,2630 & 0,0696 & 0,2647 \\
\hline 6 & 0,5353 & 0,2763 & 0,0727 & 0,2631 \\
\hline 7 & 0,5354 & 0,2869 & 0,0752 & 0,2619 \\
\hline 8 & 0,5354 & 0,2957 & 0,0771 & 0,2609 \\
\hline 9 & 0,5356 & 0,3029 & 0,0788 & 0,2601 \\
\hline 10 & 0,5356 & 0,3092 & 0,0802 & 0,2592 \\
\hline 11 & 0,5358 & 0,3145 & 0,0813 & 0,2586 \\
\hline 12 & 0,5360 & 0,3193 & 0,0824 & 0,2580 \\
\hline 13 & 0,5360 & 0,3234 & 0,0833 & 0,2574 \\
\hline 14 & 0,5360 & 0,3270 & 0,0841 & 0,2571 \\
\hline 15 & 0,5364 & 0,3303 & 0,0848 & 0,2567 \\
\hline 16 & 0,5362 & 0,3333 & 0,0854 & 0,2562 \\
\hline 17 & 0,5362 & 0,3364 & 0,0860 & 0,2556 \\
\hline 18 & 0,5368 & 0,3380 & 0,0865 & 0,2559 \\
\hline . & . & . & . & . \\
\hline . & . & . & . & . \\
\hline . & . & . & . & . \\
\hline 20 & 0,5394 & 0,3953 & 0,0977 & 0,2471 \\
\hline
\end{tabular}

$$
\begin{aligned}
& A=2,4 R_{0} \text { untuk } \theta<30^{\circ} \\
& A=2,0 R_{0} \text { untuk } \theta=30^{\circ} \\
& A=1,6 R_{0} \text { untuk } \theta>30^{\circ}
\end{aligned}
$$

Tabel 2. Parameter Ulir Archimedes Optimum menurut Chriss Rorres ${ }^{(5)}$.
Perancangan Pembuatan Sudu Ulir

Perhitungan panjang lintasan bentangan sudu ulir dapat dilakukan melalui 2 cara yaitu dengan perhitungan persamaan helix $L_{\text {helix }}$, persamaan (12), atau didapat dari hasil simulasi perangkat lunak gambar teknik tiga dimensi (Solidwork ${ }^{\mathrm{TM}}$ ).

$$
L_{h a l i x}=N_{h a l i x} \sqrt{\left(2 \pi R_{i}\right)^{2}+A^{2}}
$$

Jumlah helix dinyatakan dalam lambang $N_{\text {helix }}$ pada persamaan (12).

Diameter bakalan sudu D dapat dihitung berdasarkan pada panjang lintasan bentangan $L_{\text {helix }}$, yaitu :

$$
D_{i}=\frac{L_{h e l i x}}{\pi}
$$

Sesuai dengan prinsip kerja turbin ulir Archimedes bahwa berputarnya rotor turbin ulir adalah disebabkan oleh gaya berat dan gaya hidrostatis dari volume air yang berada di antara dua sudu sepanjang rotor turbin ulir. Oleh karena itu pendekatan perhitungan torsi yang dihasilkan poros turbin ulir dikaji dari 
gaya berat dan gaya hidrostatis fluida yang berada di antara dua sudu ${ }^{(7 ; 8)}$.

Perhitungan Gaya Berat

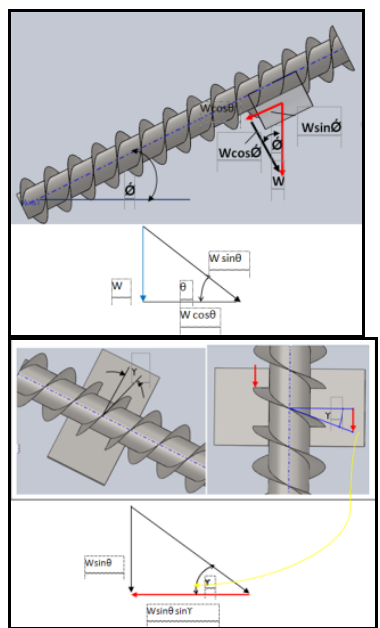

Gambar 3. Skema perhitungan torsi akibat gaya berat.

Perhitungan gaya berat air dengan volume air pada bucket dapat dihitung menggunakan persamaan (14):

$$
F_{m}=\rho * V * g
$$

Dan gaya berat arah aksial (sejajar sumbu rotor) dapat dihitung menggunakan persamaan (15) :

$$
F_{m} \sin \theta
$$

Sehingga gaya pada poros dihitung dari gaya yang terjadi pada sudut ulir dengan sudut $Y$.

$$
\begin{aligned}
& \Upsilon=(\alpha+\beta) / 2 \\
& F_{\text {tangensial }}=F_{m} \sin \theta \sin Y
\end{aligned}
$$

Torsi dari gaya berat (seperti diperlihatkan pada Gambar 3) merupakan perkalian gaya tangensial pada sudu akibat gaya berat dari volume air di bucket dengan jarak titik berat volume bucket tersebut terhadap sumbu putar.

\section{Perhitungan Gaya Hidrostatis}

Perbedaan gaya hidrostatis pada sudu turbin ulir (seperti ditunjukkan pada Gambar 4) terjadi karena adanya perbedaan head air antara head air di atas sudu (head upper) dengan head air di bawah sudu (head down). Pengurangan besar gaya hidrostatis di atas kisar dengan gaya hidrostatis di bawah kisar merupakan gaya dan menjadi torsi yang menyebabkan rotor berputar.

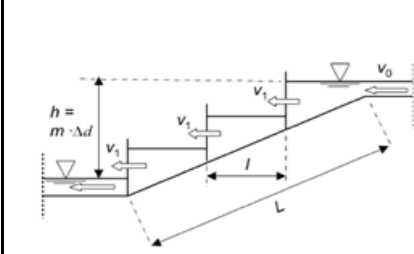

'(a)

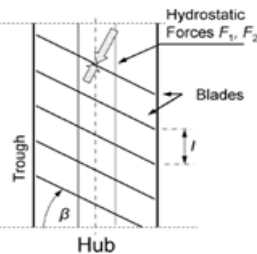

(b)

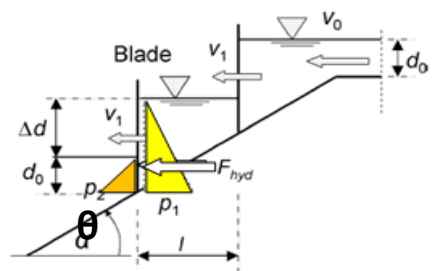

(c)

Gambar 4. Skema pendekatan gaya hidrostatis pada turbin ulir (a)Pandangan samping (b)Pandangan atas, (c) Gaya hidrostatik pada sudu ${ }^{(8)}$

Perhitungan gaya hidrostatis pada turbin ulir dapat menggunakan persamaan (18) dan (19) ${ }^{(8)}$ :

$$
F_{\text {hyd }}=\frac{\left(d_{8}+\Delta d\right)^{2}-d_{g}{ }^{2}}{2} * \rho * g
$$

$$
\begin{aligned}
& \text { Dimana } \\
& \Delta d=\frac{h}{m} \\
& h_{u}=\Delta d+d_{0} \\
& h_{d}=d_{0}
\end{aligned}
$$

Sehingga gaya hidrostatis fluida adalah:

$$
F_{h y d}=\frac{h_{u}{ }^{2}-h_{d}^{2}}{2} * \rho * g
$$

Gaya tangensial hidrostatis fluida $\left(\mathrm{F}_{\text {hyd } t}\right)$ :

$$
F_{\text {hyd } z}=F_{\text {hyd }} \cos \left(\frac{\alpha+\beta}{2}\right)
$$

\section{METODE PENELITIAN}

Penentuan dimensi sudu turbin ulir Archimedes dan sudut kemiringan poros turbin dilakukan dengan urutan langkah-langkah kegiatan:

- survei potensi sumber energi air yang cocok untuk dimanfaatkan menggunakan turbin ulir;

- mengukur head dan debit sumber energi air yang ditemukan; 
- menghitung daya yang bisa dihasilkan dari sumber energi air bersangkutan;

- menentukan dimensi sudu ulir berdasarkan pada formulasi Rorres ${ }^{(5)}$;

- perhitungan bentangan helix untuk sudu turbin ulir dan simulasi bentangan menggunakan perangkat lunak gambar teknik Solidwork ${ }^{\mathrm{TM}}$;

- Penentuan sudut kemiringan poros turbin ulir yang optimum menggunakan perhitungan torsi akibat gaya berat dan gaya hidrostatis fluida yang ada di antara 2 sudu.

\section{HASIL DAN PEMBAHASAN}

Turbin ulir yang dirancang berdasarkan potensi sumber energi air yang tersedia (lihat Gambar 5), adalah sebagai berikut:

- Head efektif : 2 meter

- Debit air :20-40 liter /detik

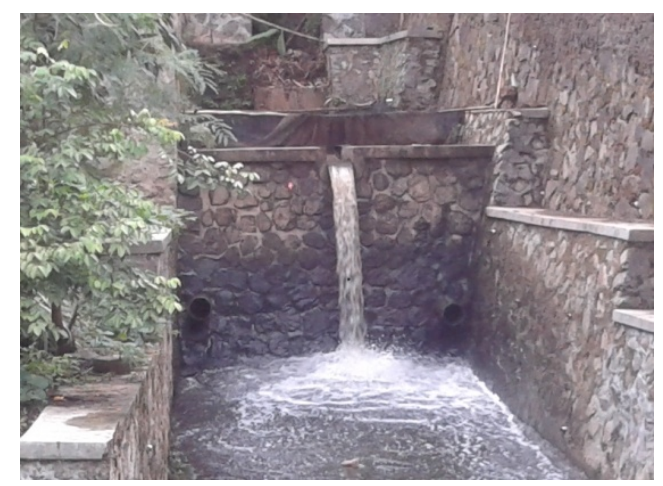

Gambar 5. Potensi sumber energi air yang akan dimanfaatkan.

Dengan demikian, mengacu pada persamaan (1), daya terbesar yang bisa dibangkitkan mencapai $392 \mathrm{~W} \leq P \leq 784 \mathrm{~W}$. Pada kenyataannya, daya yang dibangkitkan akan lebih rendah dari pada daya di atas karena efisiensi turbin ulir dan efisiensi generator listrik .

Sudut kemiringan turbin ulir $\vartheta$ yang akan dibuat ditetapkan sebesar $30^{\circ}$, maka pada head $2 \mathrm{~m}$, panjang poros turbin ulir $L$ yang dibutuhkan adalah 3,46 m, yaitu dihitung dari persamaan (2). Diameter dalam turbin ulir $R_{i}$ pada perancangan dipilih sebesar $0,01095 \mathrm{~m}$, yaitu diameter luar pipa 8 inci yang digunakan sebagai poros turbin.

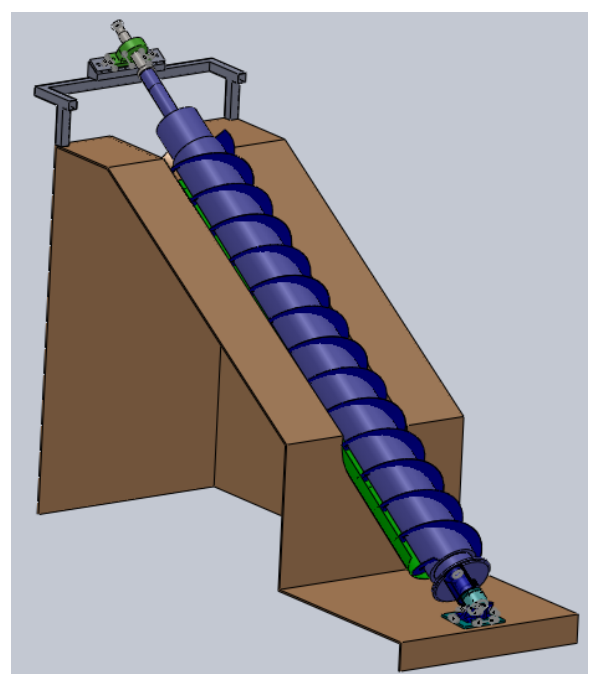

Gambar 6. Isometrik rancangan turbin ulir Archimedes.

Dalam penentuan dimensi sudu turbin ulir ini dipilih jumlah sudu ulir $N$ sebanyak 2 . Mengacu pada tabel 2 untuk $N=2$ dipilih :

- $\rho^{*}=0,5369$;

- $\lambda^{*}=0,1863$ dan

- $v^{*}=0,2747$

Maka didapatkan:

- Jari-jari luar $R_{o}=0,204 \mathrm{~m}$

- Panjang kisar $\Lambda=0,413 \mathrm{~m}$

- $\nu^{\mathrm{T}}=0,014857 \mathrm{~m}^{3}$;

- Jumlah kisar $m=8,37$; dan

- $V^{T}$ pada seluruh sudu $=0,124 \mathrm{~m}^{3}$.

Panjang lintasan bentangan sudu ulir dihitung menggunakan persamaan (12) untuk helix $\left(N_{\text {helix }}=1\right.$ ), yaitu $L_{\text {hellx }}=0,802 \mathrm{~m}$ (lihat Gambar 7). Kemudian perangkat lunak gambar teknik (lihat Gambar 8) menghasilkan perhitungan panjang lintasan bentangan sudu $L_{\text {helix }}$ sebesar $0,802 \mathrm{~m}$, sama dengan angka yang diperoleh dari persamaan (12). 


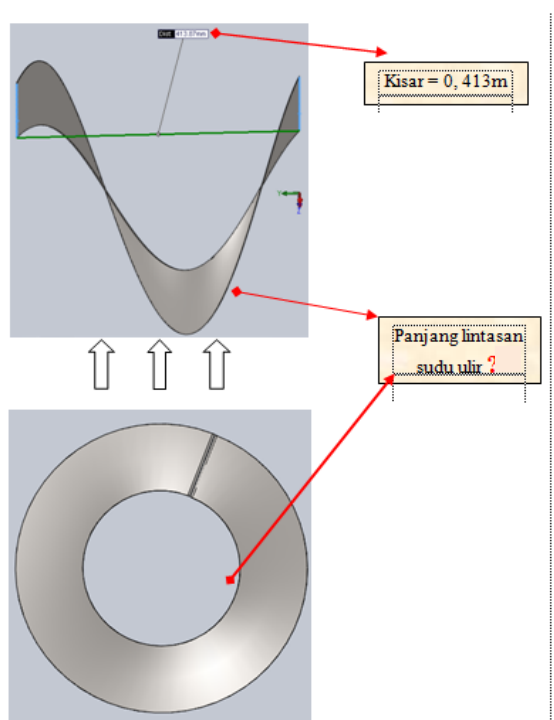

Gambar 7. Panjang lintasan bentangan satu kisar sudu ulir.

Dari hasil perhitungan panjang lintasan bentangan sudu di atas, maka diameter bakalan sudu dapat dihitung melalui persamaan (13). Hasilnya $D_{i}=0,255 \mathrm{~m}$ (lihat Gambar 9).

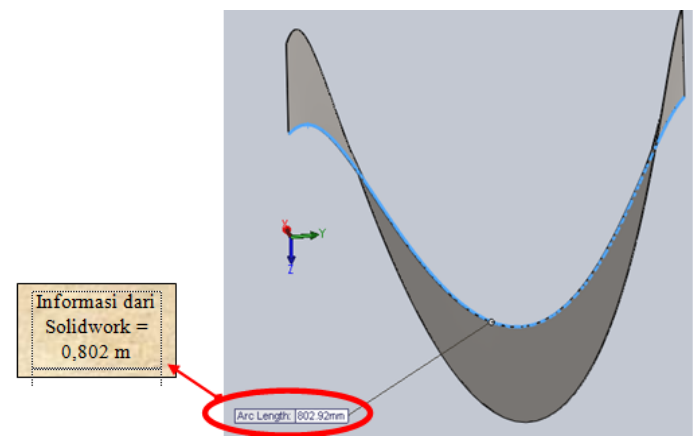

Gambar 8. Panjang lintasan bentangan satu kisar sudu ulir hasil SolidWork ${ }^{\mathrm{TM}}$.

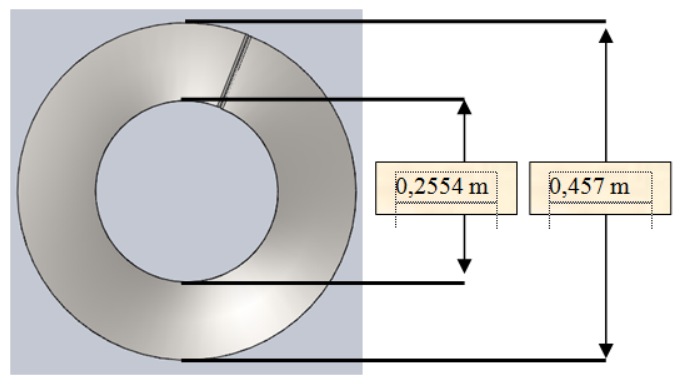

Gambar 9. Dimensi bakalan satu kisar sudu turbin.

Hasil perhitungan torsi akibat gaya berat dan gaya hidrostatis dengan volume bucket maksimum ditunjukkan pada gambar 10 dimana sudut optimum kemiringan poros $(\theta)$ adalah pada sudut $32^{\circ}$ yang dapat menghasilkan torsi terbesar.

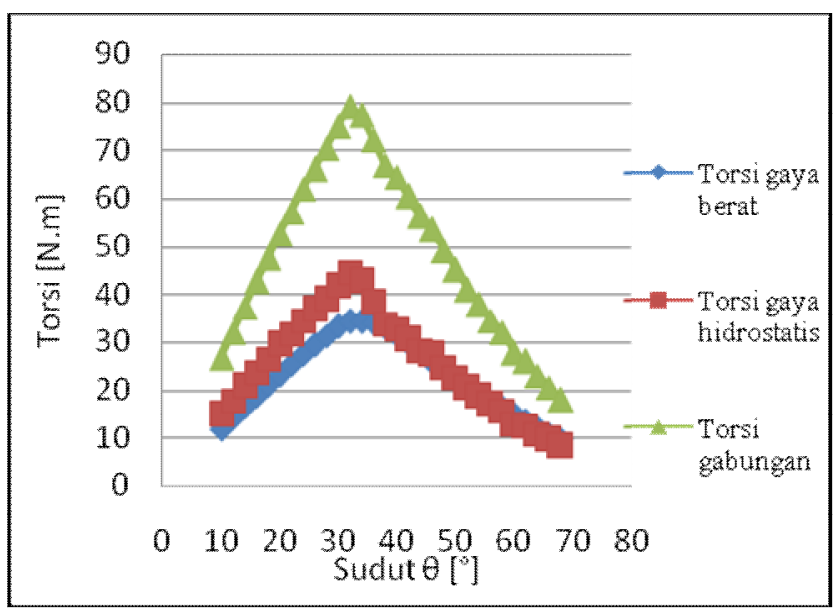

Gambar 10. Grafik pengaruh sudut $(\theta)$ kemiringan poros terhadap torsi akibat gaya berat dan gaya hidrostatis.

Besar sudut kemiringan poros berpengaruh terhadap banyaknya volume air pada ruang di antara dua sudu (bucket). Pada sudut di atas $32^{\circ}$, banyaknya air pada bucket akan semakin berkurang karena sebagian volume air akan mengalir pada bagian atas sudu ulir dan tidak mnghasilkan gaya pada poros.

Pada Gambar 11,12 dan 13 diperlihatkan bentuk air pada volume bucket pada saat sudut kemiringan poros $32^{\circ}$ dan $68^{\circ}$, dimana volume air pada bucket dengan sudut $\theta=68^{\circ}$ lebih sedikit dari pada volume air pada bucket dengan sudut $\theta=32^{\circ}$.

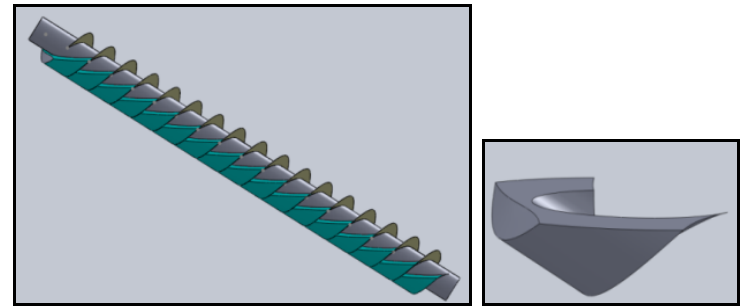

Gambar 11. Bentuk air pada volume bucket sebesar $0,120 \mathrm{~m}^{3}$ sudut $(\theta)$ kemiringan poros $32^{\circ}$.

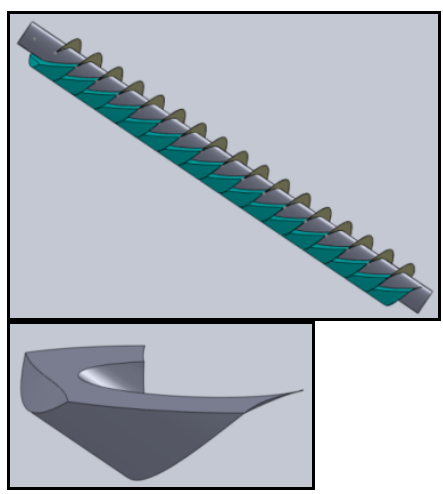


Gambar 12. Bentuk air pada volume bucket sebesar $0,110 \mathrm{~m}^{3}$ dengan sudut $\theta$ kemiringan poros $34^{\circ}$.
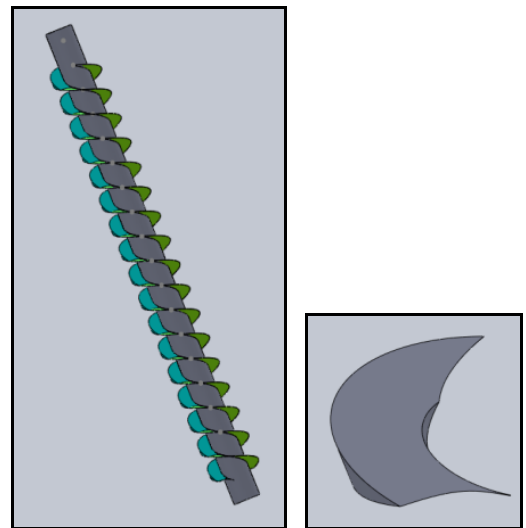

Gambar 13. Bentuk air pada volume bucket sebesar $0,0154 \mathrm{~m}^{3}$ sudut $(\theta)$ kemiringan poros $68^{\circ}$.

\section{KESIMPULAN DAN SARAN}

Dari penelitian penentuan dimensi sudu turbin dan sudut kemiringan poros turbin ulir Archimedes ini maka dapat disimpulkan sebagai berikut:

1. Penentuan dimensi turbin ulir menggunakan formulasi Rorres dilakukan untuk mengoptimumkan volume bucket pada sudu turbin.

2. Penentuan bakalan bentangan sudu turbin dapat menggunakan persamaan helix atau informasi perangkat lunak gambar teknik.

3. Kinerja turbin ulir telah diperoleh dari penelitian ini, dimana hasil perhitungan gaya berat dan gaya hidrostatis pada volume bucket maksimum diperoleh sudut optimum pada sudut $\theta=32^{\circ}$.

\section{Ucapan Terima Kasih}

Penulis mengucapkan terimakasih kepada POLMAN Bandung yang telah memfasilitasi penelitian ini.

\section{DAFTAR PUSTAKA}

1. Havendri, A. dan Arnif, I., 2010. Kaji Eksperimental Penentuan Sudut Ulir Optimum pada Turbin Ulir untuk Data Perancangan Turbin Ulir pada PLTMH dengan Head Rendah, Prosiding SNTM IX, Seminar Nasional Tahunan Teknik Mesin ke-19, 13-15 Oktobar 2010, Palembang, Indonesia.

2. Hellmann, H., 2003. Gutachten zur Wirkungsgradbestimmung einer Wasserkraftschnecke Fabrikat Ritz-Atro [Report on determination of hydraulic screw efficiency manufactured by RitzAtro Ltd.], Fachbereich Maschinenbau und Verfahrenstechnik, Technical University, Kaiserslautern, Germany.

3. http://www.gess.cz/en/small-water-plantarchimedean-screw-turbine.html, diakses tanggal 2 Juli 2011.

4. The British hydropower association, 2005. A guide to UK mini-hydro developments, The British hydropower association.

5. Rorres, C., 2000. The Turn of the Screw :Optimal design of an archimedes, Journal of Hydraulic Engineering, 126(1), pp.72-80.

6. Nagel, G., 1968. Archimedean Screw Pump Handbook, Prepared for Ritz-Atro Pumpwerksbau GMBH Roding, Nürnberg, Germany.

7. Nagel, G., Radlik, K., 1988. Wasserförderschnecken [Water lifting screws] Bauverlag, Wiesbaden/Berlin, German.

8. Muller, G., 2009. Simplified Theori of Archimedean Screw, Journal of Hydraulic Engineering, Vol.47, No.5. 